\title{
Response Assessment in Neuro-Oncology Criteria
}

National Cancer Institute

\section{Source}

National Cancer Institute. Response Assessment in Neuro-Oncology Criteria. NCI

Thesaurus. Code C114879.

An update to the MacDonald criteria for assessing disease progression and treatment response in glioblastoma multiforme (GBM). 